Price Sarah (Orcid ID: 0000-0001-7722-3171)

Sumithran Priya (Orcid ID: 0000-0002-9576-1050)

\title{
Abstract
}

The prevalence of women of child-bearing age with obesity continues to rise at an alarming rate. This has significant implications for both the short- and long-term health of mother and offspring. Given the paucity of evidence-based literature in this field, the preconception management of women with obesity is highly variable both between institutions and around the world. This systematic review aims to evaluate studies that inform us about the role of preconception weight loss in the fertility and pregnancy outcomes of women with obesity. Current therapeutic interventions are discussed, with a specific focus on the suitability of weight loss interventions for women with obesity planning pregnancy. There are significant knowledge gaps in the current literature; these are discussed and areas for future research are explored.

This is the author manuscript accepted for publication and has undergone full peer review but has not been through the copyediting, typesetting, pagination and proofreading process, which may lead to differences between this version and the Version of Record. Please cite this article as doi: $10.1111 /$ obr.12804

This article is protected by copyright. All rights reserved. 


\subsection{Introduction}

The prevalence of women of child-bearing age with overweight (BMI $25-29.9 \mathrm{~kg} / \mathrm{m}^{2}$ ) and obesity $\left(\mathrm{BMI} \geq 30 \mathrm{~kg} / \mathrm{m}^{2}\right)$ is increasing rapidly $(1,2)$. In 1993 , the prevalence of overweight and obesity in women aged $26-29$ years old was $33.3 \%$ but only 20 years later, the prevalence of overweight and obesity in this age group was $47.3 \%(3,4)$. Currently in Australia, $26.3 \%$ of women are overweight and $24.0 \%$ of women have obesity $(5,6)$. It is predicted that over the next decade, the greatest increase in the prevalence of obesity will occur in women of reproductive age (7). Studies across numerous developed nations demonstrate that obesity disproportionately affects women belonging to lower socioeconomic groups (8), those with lower levels of education (9) and those of certain ethnic groups $(10,11)$.

A recent study compared the national guidelines for the management of obesity in women of reproductive age in Australia, Canada, Ireland, United Kingdom and the United States of America (12). All five national guidelines broadly recommended weight loss in pre-pregnant women with obesity but the advice regarding the amount and method of weight loss varied considerably (12). In part, this variation occurs because clinical practice guidelines for pre-pregnancy weight management are largely based on local consensus opinion.

A study by Callaway et al. demonstrated that barriers to addressing overweight and obesity include poor uptake of routine pre-pregnancy care and inaccurate self-categorisation of weight (13).

This article is protected by copyright. All rights reserved. 
Of those meeting a medical definition of obesity $\left(\mathrm{BMI} \geq 30 \mathrm{~kg} / \mathrm{m}^{2}\right)$, women reported their weight as normal $(8 \%)$, overweight $(76 \%)$ or obese $(16 \%)$. Of the women with obesity, $78 \%$ sought a preconception review with a doctor, but only $28 \%$ were advised to lose weight (13). Unfortunately, the women who were advised to lose weight prior to conception were no more likely to lose weight than those who did not receive this advice (13). The inadequate delivery of advice regarding prepregnancy weight loss, and the unsuccessful nature of weight loss attempts, clearly need to be addressed $(14,15)$.

Regardless of whether considering fertility, pregnancy outcomes, or the long-term health of the mother and child, there is strong evidence of increased risks of adverse outcome where the mother has obesity prior to conception $(16,17,18,19,20)$. It may be ideal for a woman to enter pregnancy at a 'normal' weight (BMI 18.5 to $<25.0 \mathrm{~kg} / \mathrm{m}^{2}$ ) (12), but currently almost half of women have overweight or obesity when they conceive $(4,16,21)$. Whilst acknowledging that the evidence regarding pre-pregnancy weight management is incomplete and would benefit from the addition of large well-designed randomised controlled trials, it is imperative that the available evidence is clearly summarised and clinical decisions are guided by this evidence.

\subsection{Rationale for management of obesity pre-conception}

\subsection{Fertility and assisted reproductive outcomes}

Women with obesity are more likely to suffer ovulatory and endometrial dysfunction, altered oocyte quality, and infertility compared to normal weight women $(22,23)$. In both women who conceive spontaneously and those who conceive using reproductive technology, the rate of conception is lower in women with obesity than normal weight counterparts $(24,25,26)$. While

This article is protected by copyright. All rights reserved. 
most obstetric care providers have policies around the care of women with obesity during pregnancy, there is significant variation in how fertility clinics manage obesity (27). A study of fertility centres in the United States reported that $16 \%$ had no policy regarding obesity, while $21.4 \%$ did not offer in vitro fertilization (IVF) to women with $\mathrm{BMI}>35-40 \mathrm{~kg} / \mathrm{m}^{2}(27)$.

Weight loss in women with obesity is known to improve fertility rates (28). Some studies suggest that as little as $5 \%$ body weight loss may be enough to re-establish normal ovulation in a woman with anovulatory infertility due to obesity $(26,28,29,30)$. Kort et al. demonstrated that $>10 \%$ weight loss improves pregnancy rate more than lesser degrees of weight loss ( $88 \%$ vs $54 \%$, $p=0.049)(28)$. However, the amount of weight loss and method of weight loss to optimise fertility is unknown.

\subsection{Pregnancy outcomes}

The impact of maternal obesity on pregnancy outcomes has been well described $(16,31)$. Maternal risks include increased risk of miscarriage (32), gestational diabetes $(33,34)$, gestational hypertension and pre-eclampsia $(35,36)$, induced labour, caesarean section (34), anaesthetic complications and wound infections (16). Mothers with obesity are less likely to initiate and maintain breastfeeding (37).

Increasing maternal BMI is associated with an increasing risk of perinatal death $(38,39,40)$. In 2014, Aune et al. demonstrated that the risk ratio per 5-unit increase in maternal BMI for fetal death was $1.21(95 \% \mathrm{Cl}, 1.09-1.35)$ and for stillbirth was $1.24(95 \% \mathrm{Cl}, 1.18-1.30)(17)$. Women with obesity are also more likely to spontaneously deliver pre-term ( $<37$ weeks' gestation) and extremely pre-term (<32 weeks' gestation) infants (41). Neonatal risks of maternal obesity include large-for-gestational age (LGA) (42), neonatal hyperbilirubinemia, neonatal hypoglycaemia (16) and an increased risk of

This article is protected by copyright. All rights reserved. 
congenital malformation $(43,44)$. In a retrospective study in France, the risk of neonatal intensive care admission was 3.5 higher when the mother had obesity compared to mothers of normal weight (45).

While the focus of this review is on preconception management of women with obesity, the relationship of maternal obesity with gestational weight gain and post-partum weight retention should not be overlooked. The risks of maternal obesity on pregnancy outcomes are further increased by excessive gestational weight gain $(46,47,48)$. For example, Black et al. notes that while both pre-pregnancy obesity and excessive gestational weight gain are independent risk factors for a large-for-gestational age fetus, the combination of these risk factors is additive (47). Post-partum weight retention contributes significantly to interpregnancy weight gain and therefore to maternal weight prior to the subsequent pregnancy. Sumithran et al. reported a gain of $\geq 4 \mathrm{~kg} / \mathrm{m}^{2}$ between the first two pregnancies in $7.5 \%$ of normal weight women, $10.5 \%$ of overweight women, and $13.4 \%$ of women with obesity (49).

Excellent obstetric care likely moderates the maternal risks associated with increasing BMI. Current protocols recommend that women of high BMI (usually BMI $\geq 40 \mathrm{~kg} / \mathrm{m}^{2}$ ) are referred to tertiary obstetric centres and receive more regular antenatal monitoring (12). Increased care results in higher maternity costs (50). Morgan et al. notes that adjusting for maternal age, parity, ethnicity and comorbidity, mean total costs were $23 \%$ higher among overweight women (RR $1.23,95 \% \mathrm{Cl}$ 1.230- 1.233) and $39 \%$ higher among women with obesity (RR 1.39, $95 \% \mathrm{Cl} 1.38-1.39$ ) compared with women with normal weight (51). For both medical and economic reasons, it is imperative that we shift our focus from harm minimization to prevention.

\subsection{Long term risks for the baby}

This article is protected by copyright. All rights reserved. 
Emerging evidence suggests that the metabolic status of the mother during pregnancy may 'program' the offspring's long-term risk of metabolic disease (52). Maternal obesity, glycaemic control and dietary intake during pregnancy all contribute to the metabolic state of the mother (53, 54). This in-utero environment impacts growth and development of the fetus and may alter the epigenome, which determines the expression of the genetic code, and thereby may drive changes in the metabolic phenotype of the child $(55,56,57)$. Consistent with this, studies show that a child born large-for-gestational-age to a mother with gestational diabetes has a $50 \%$ risk of developing components of the metabolic syndrome, such as obesity, by the time they start school $(58,59)$. Obesity in childhood is known to be the most significant risk factor for obesity in adulthood $(18,53$, $60)$.

\subsection{Long term risks for the woman of reproductive age with obesity}

The association between obesity and cardiovascular disease is well established (61). Maternal obesity in pregnancy is independently associated with both all-cause mortality and risk of hospital admission for a cardiovascular event $(61,62)$. Pre-pregnancy obesity increases the risk of gestational diabetes (16). Of women with gestational diabetes, $70 \%$ will develop type 2 diabetes within the subsequent decade (63). Women with obesity who develop gestational diabetes have a significantly increased long-term risk of renal disease (64) and left ventricular dysfunction $(65,66,67)$ compared to normal weight women who develop gestational diabetes.

\subsection{Rationale for systematic review}

Preconception care involves interventions which improve the physical and/or mental well-being of women prior to conception in order to increase the likelihood of a successful pregnancy and healthy offspring (15). In 2015, a Cochrane Systematic Review was conducted to evaluate the

This article is protected by copyright. All rights reserved. 
effectiveness of preconception interventions for women with overweight or obesity to improve pregnancy outcomes (68). However, the authors were unable to complete the review given they found no articles meeting the inclusion criteria. While this clearly demonstrates the need for further research in this area, it provides no guidance on the current clinical care of women with obesity who are planning pregnancy.

The evidence supporting the negative impact of obesity on pregnancy outcomes is undeniable (16). It is therefore appropriate that clinicians discuss this information with their patients (12). For women who want to reduce the risks associated with obesity in pregnancy, the next logical step is to seek information about the optimal method and amount of weight loss to reduce these risks. Given the growing population of women with obesity who are planning pregnancy, and the complex nature of performing pre-conception weight management trials, it is inadequate that we wait until large randomised controlled trials are available before we assess the current literature and inform our patients accordingly.

This systematic review is intended to assess the current literature on preconception weight loss in women with overweight and obesity. The inclusion criteria are deliberately more flexible than the 2015 Cochrane review (68) such that the available literature can be assessed and utilised in the development of clear guidelines for clinicians. Furthermore, systematic review of the existing literature will facilitate the use of the protocols, results and limitations of these studies in informing the design of future pre-conception weight loss studies.

\subsection{Systematic review}

\section{Study selection}

This article is protected by copyright. All rights reserved. 
Electronic databases (Medline, PubMed, Embase, Cochrane Library) were searched from 1980 until May 2018. The search was filtered to only include original research studies in women with overweight and/or obesity that have been published in the English language. Meta-analyses, systematic reviews and case reports were not included. All other studies meeting these criteria were considered for inclusion if the population comprised exclusively women with overweight and/or obesity, subjects were recruited, and the intervention was delivered prior to conception, and a pregnancy-related outcome was evaluated. Studies must have been published in full; research available only in abstract form was excluded.

Non-surgical weight loss studies were included if the method of weight loss and duration of intervention were described. In this review, if mean weight loss was not specified in kilograms, mean BMI was converted to weight in kilograms assuming the standard female height of $162 \mathrm{~cm}(69)$. The presence of co-morbidities (e.g. reversible infertility, polycystic ovarian syndrome (PCOS)) in the study population did not exclude the study, providing that future pregnancy was possible. The method of conception (i.e. spontaneous, assisted reproductive technology) did not influence whether a study was included. Surgical weight loss studies were included only if each of the following was reported: pre-surgical weight, pre-conception weight and time to conception.

A search strategy was developed for all databases using the following search terms: (obesity OR overweight) AND (pregnan* OR prepregnancy OR preconception). A search was then conducted for non-surgical methods of weight loss using the following search terms: (diet OR exercise OR lifestyle OR (very low energy diet) OR psychological OR behavio* OR pharmacotherapy). A separate search was conducted for surgical methods of pre-conception weight loss using the search terms: ((bariatric surgery) OR (gastric bypass) OR sleeve OR roux-en-Y OR (laparoscopic adjustable band*)

This article is protected by copyright. All rights reserved. 
OR (gastric band*) OR (intragastric balloon)). Non-surgical and surgical weight loss searches were then combined with the initial search terms.

The complete search strategy used in the electronic database MEDLINE is described in Supplementary Table 1 for non-surgical methods of pre-conception weight loss and Supplementary Table 2 for surgical methods of pre-conception weight loss.

Obesity is defined as a body mass index $\geq 30 \mathrm{~kg} / \mathrm{m}^{2}$. Overweight is defined as a body mass index $25.0-29.9 \mathrm{~kg} / \mathrm{m}^{2}$. Pregnancy is defined as the presence of one or more gestational sacs diagnosed by ultrasound or definitive clinical signs of pregnancy (70). Pre-pregnancy and preconception refers to the period preceding fertilization of the ovum and implantation in the reproductive tract (70). Preconception care is any health encounter during a woman's reproductive life, including counselling on medical care and behaviours, that is intended to optimise pregnancy outcomes (71).

Two reviewers (SP and PS) identified articles that met the above inclusion criteria. The titles and abstracts of all studies identified by the search were scanned and the full text of eligible studies was retrieved for further evaluation. Additional studies were identified by examining the bibliographies of full text articles that were assessed for eligibility. Any disagreement about inclusion was resolved by consensus.

\section{Data extraction}

Study details (authorship, year of publication, study design, type of intervention, study period), characteristics of the study population (sample size, number of women, proportion of women with overweight or obesity), weight loss, and pregnancy-related outcomes were extracted.

This article is protected by copyright. All rights reserved. 
For this review, the main outcome of interest was maternal weight loss prior to conception with respect to the primary outcome of the original study (e.g. fertility rate, live birth rate, or maternal or fetal outcome). Non-surgical and surgical methods of weight loss were examined separately.

\section{$\underline{\text { Quality assessment }}$}

The McMaster quality assessment tool was used to assess quality of the selected articles. This tool rates articles based on eight criteria- selection bias, study design, confounders, blinding, data collection methods, withdrawal/drop-outs, intervention integrity and analyses. Component ratings are used to generate a global rating of STRONG (no weak rating), MODERATE (one weak rating) or WEAK (two or more weak ratings). Two reviewers (SP and PS) rated each article and discrepancies were resolved by consensus (Table 1 and Table 2).

\subsection{Results}

As outlined in Figure 1, the database search resulted in 3249 articles related to non-surgical weight loss. An additional 3 articles were identified in the bibliographies of extracted articles. After removal of duplicates ( $n=2265$ ) and unsuitable abstracts ( $n=926), 61$ full-text articles were identified. A further 48 articles were removed due to the study design $(n=16)$, the study not being preconception $(n=15)$, the study population not being exclusively overweight/obese $(n=8)$ and the study not being related to fertility or pregnancy outcomes $(n=9)$. In total, 13 non-surgical weight loss studies met the pre-specified criteria for inclusion in this systematic review (shown in Table 3).

As outlined in Figure 2, the database search resulted in 538 articles related to surgical weight loss. An additional 2 articles were identified in the bibliographies of extracted articles. After removal of duplicates ( $n=356)$ and unsuitable abstracts ( $n=127), 57$ full-text articles were identified. A further 41 articles were removed due to study design ( $n=10)$, no pre-surgical weight being specified $(n=7)$,

This article is protected by copyright. All rights reserved. 
no preconception weight being specified $(n=14)$, the study population not planning pregnancy $(n=6)$ and the study outcomes being related to childhood outcomes rather than fertility/pregnancy outcomes $(n=4)$. In total, 16 surgical weight loss studies met the pre-specified criteria for inclusion in this systematic review (shown in Table 4).

\subsection{Non-surgical Pre-pregnancy Weight Loss}

\subsubsection{Characteristics and quality of included studies}

Thirteen studies were identified as investigating the impact of non-surgical pre-conception weight loss on fertility and/or pregnancy outcomes in women with overweight or obesity (Table 3). Six studies were identified as being of weak quality and seven were of moderate quality. No studies were high quality. Pre-pregnancy weight loss studies are generally unblinded studies. Furthermore, multiple factors can impact fertility and pregnancy outcomes. If these factors are used as the study outcome, confounders must be considered. Studies included in this review that, in addition to being small, lacked a control arm and/or failed to consider confounding factors were deemed of weak quality. Although four large studies $(n>100)$ were included in the review, the quality of these studies was affected by a high drop-out rate $(72,73,74,75)$. The large randomised controlled trial by Mutsaerts et al. (74) reported a drop-out rate of $24 \%$ in the intervention arm. Similarly, a smaller randomised controlled trial by Becker et al. had a drop-out rate of $58 \%$ in the intervention arm (76). Two studies in this review $(28,73)$ had set weight loss targets, but offered a range of interventions to reach this weight target. In these studies, the exact intervention used is unclear.

The duration of the interventions varied between 27 days and 6 months in the included nonsurgical weight loss studies. Unfortunately, weight loss is reported inconsistently as either change in weight $(72,74,77,78,79,80,81)$, change in percent body weight $(28,73)$ or change in $\mathrm{BMI}(82)$, but 
rarely both change in $\mathrm{BMI}$ and weight $(75,76,83)$. This makes direct comparison between studies difficult. In the study where only change in BMI was reported (82), this was converted to change in weight (as described in section 4.0). Fertility was used as the primary outcome in all but one (82) non-surgical weight loss study. All studies except two $(72,77)$ included live birth rate as a secondary outcome. Time to conception and pregnancy loss $<20$ weeks' gestation were variably reported.

\subsubsection{Impact of lifestyle intervention}

Six studies used diet, exercise and psychological support as the weight loss intervention (72, 74, 76, 77, 79, 84). Dietary advice varied considerably between studies, but most involved a hypocaloric diet $(28,72,77)$. In the study by Moran et al. (81), meal replacements were used to reduce calorie intake, while the hypocaloric diet in the study by Becker et al. (76) was specifically low glycaemic load. Some studies conducted group exercise sessions $(77,79,84)$ while others only provided exercise advice $(28,72,81,83)$. Only the study by Galletly et al. (84) specifically provided psychological care, while two studies provided behavioural counselling $(74,83)$. Most studies achieved weight loss between 4-6kg regardless of the method (diet, exercise, behavioural intervention or a combination) or duration of the study. However, two small studies $(79,82)$ did achieve much larger weight loss (mean weight loss $10.2 \pm 4.3 \mathrm{~kg}$ and $26.0 \pm 3.5 \mathrm{~kg}$ respectively). Unfortunately, most of the 'lifestyle intervention' studies did not have a control group. The study by Becker et al. (76) is a notable exception, where women in the intervention arm achieved more weight loss than the control group $(4.51 \pm 0.83 \mathrm{~kg}$ vs $0.72 \pm 0.75 \mathrm{~kg}, \mathrm{p}<0.05)$.

\subsubsection{Impact of Very Low Energy Diet interventions}

Several studies used a Very Low Energy Diet (VLED) program to achieve weight loss (73, 75, $80,81,83)$. However, two programs $(80,81)$ used VLED in combination with a carbohydrate containing diet and hence it is questionable whether women would have achieved ketosis. Mean 
weight loss in the intervention arms of these studies was $5.6 \mathrm{~kg}$ and $3.8 \mathrm{~kg}$ respectively which is comparable to lifestyle programs. One study (73) used a VLED program in combination with weight loss medication hence it is not possible to determine the impact of the VLED alone. Only the studies by Sim et al. (83) and Einarsson et al. (75) used a complete VLED program such that ketosis was likely. Both studies used the VLED program immediately prior to in vitro fertilization (IVF). Sim et al. (83) used a 6-week VLED program followed by a 6-week lifestyle program and achieved weight loss of $6.6+/-4.6 \mathrm{~kg}$ in the intervention arm, whilst Einarsson et al. (75) used a 12-week VLED program followed by a 4-week lifestyle program and achieved weight loss of 9.4+/-6.6kg.

\subsubsection{Impact of Pharmacological interventions}

Three studies used pharmacotherapy to achieve weight loss $(28,72,73)$. Tang et al. (72) compared the use of metformin plus lifestyle with lifestyle alone. Both weight loss $(2.8 \mathrm{~kg}$ vs $1.5 \mathrm{~kg}$, $\mathrm{p}=0.06)$ and pregnancy rate $(8.7 \%$ vs $2.7 \%, \mathrm{p}=0.23)$ were higher in the lifestyle plus metformin group but these differences were not statistically significant. Kort et al. (28) used a combination of lifestyle, metformin and phentermine. Those achieving $>10 \%$ weight loss were compared with those achieving $<10 \%$ weight loss. In those achieving $>10 \%$ weight loss, pregnancy rate was higher ( $88 \%$ vs $54 \%, p=0.049)$ and live birth rate was higher ( $71 \%$ vs $37 \%, p=0.02)$. Similarly, the study by Legro et al. (73) compared the use of the combined oral contraceptive pill (COCP) with $>7 \%$ weight loss achieved with sibutramine, orlistat and exercise and a combination approach prior to ovulation induction. The two arms assigned to weight loss achieved more weight loss ( $0 \%$ vs $6.2 \%$ vs $6.4 \%, p$ $<0.001)$ and higher live birth rates ( $10 \%$ vs $26 \%$ vs $24 \%, p=0.82$ ).

\subsection{Surgical Pre-pregnancy Weight Loss}

\subsubsection{Characteristics and quality of included studies}

This article is protected by copyright. All rights reserved. 
Fifteen studies were identified as investigating the impact of surgical pre-conception weight loss on fertility/pregnancy outcomes in women with overweight or obesity (Table 4). The quality of the studies included was generally weak. Most studies were retrospective audits with data derived from medical coding data. Such studies were non-randomised and non-blinded, having the potential for selection bias. Further, confounding factors such as parity, age, ethnicity and smoking status have not been taken into account. A notable exception is the study by Johansson et al. (85) which is of moderate quality and contains a relatively large cohort of women (85). There were two other moderate quality studies identified $(86,87)$. The study by Dixon et al. $(86)$ was a prospective study with a moderate sample size. The study by Sheiner et al. (87) was a retrospective study but has a large sample size and compares pregnancy outcomes with respect to surgery type.

The most common bariatric surgical procedures included in this review are sleeve gastrectomy, laparoscopic adjustable gastric banding (LAGB), and Roux-en-Y gastric bypass (RYGB). Pre-surgery BMI varied between $35.1 \mathrm{~kg} / \mathrm{m}^{2}$ and $52.8 \mathrm{~kg} / \mathrm{m}^{2}$. In order to be included in the review, studies needed to specify body weight loss (in kilograms) achieved between pre-surgery and conception. This is distinct from percent of 'excess weight loss' or percent of 'excess fat mass' which are commonly reported in bariatric surgery studies.

Conception rates and live birth rates could not be reported in ten included studies given that these were retrospective cohort studies comprising women who had a pregnancy/live birth after bariatric surgery. Live birth rate was reported in four studies $(88,89,90,91)$. Almost all studies used pregnancy outcomes as the primary study outcome. Three studies $(88,89,92)$ used fertility rate as the primary outcome but reported pregnancy outcomes as a secondary outcome. Unfortunately, there was no uniform way in which pregnancy outcomes were reported.

This article is protected by copyright. All rights reserved. 


\subsubsection{Impact of bariatric surgery}

This review included five studies of women who had undergone LAGB prior to pregnancy. Mean weight loss post-LAGB varied between $22-28 \mathrm{~kg}$. Time to conception varied between $12-37$ months. One study (88) had fertility as a primary outcome. In this study, no adverse pregnancy outcomes were noted in those pregnancies that resulted in a live birth. The remaining studies (86, 91, 93, 94) reported lower rates of gestational diabetes $(86,93)$ and gestational hypertension/preeclampsia $(86,93,94)$ in women who had undergone bariatric surgery compared with matched women with obesity $(86,93,94)$ and normal weight controls $(94)$. The small study by Weiss et al. (91), reported no adverse pregnancy outcomes but did report 2 cases of band slippage.

Two studies recruited women post-sleeve gastrectomy. The small study by Han et al. (95) reported a weight loss of $28 \mathrm{~kg}$ prior to pregnancy; no maternal or fetal pregnancy outcomes were reported. The study by Ducarme et al. (96) reported a surgery-induced weight loss of $43 \mathrm{~kg}$ prior to pregnancy. In women who had surgery, higher rates of pre-term delivery were reported. Interestingly, the rate of small-for-gestational-age (SGA) infants was higher in women who still had obesity after surgery $(96)$. In both studies $(95,96)$, the mean time to conception was approximately 12 months.

Two studies included women who had had conceived after undergoing RYGB $(89,97)$. The study by Jamal et al. (89) reported a mean weight loss of $51 \mathrm{~kg}$. This study was small $(n=6)$ and all participants conceived. However, pregnancy outcomes were not reported. Santulli et al. (97) reported a mean weight loss of $48 \mathrm{~kg}$ post-RYGB with a mean time to conception of 26 months. This is consistent with the current surgery to pregnancy interval suggested in bariatric surgery guidelines.

This article is protected by copyright. All rights reserved. 
Pregnancy outcomes in the surgery group were compared with matched controls; higher rates of caesarean section and small-for-gestational-age infants was again noted.

Seven studies included women who had undergone one of several types of bariatric surgery prior to conception. Mean surgery-induced weight loss prior to pregnancy ranged from 24.0 to 49.5kg. In all studies, mean time to conception was $>24$ months with the exception of the study by Bebber et al. (90) which specifically examined the impact of the surgery to conception interval on pregnancy outcomes. Of the studies which included a mix of bariatric surgery types, three studies reported lower rates of maternal gestational diabetes $(90,98,99)$, one reported lower rates of gestational hypertension (98) and one reported a lower rate of LGA infants (85). However, three studies reported a higher rate of SGA infants $(41,99,100)$.

\subsection{Discussion}

Given the clear link between obesity and adverse pregnancy outcomes, it is reasonable to expect that clinicians should discuss these risks with women planning pregnancy. While the lack of large prospective randomised controlled trials in the pre-pregnancy setting must be acknowledged, the available data provide some guidance on what can be expected from existing weight management strategies. This can assist the patient and clinician to be clear about realistic weight loss targets and potential consequences of the various weight loss strategies.

In the non-surgical weight loss studies, weight loss is modest (3-6kg). This is consistent with data from lifestyle studies in adults such as the Counterweight study (101).This is an important finding given that the international guidelines for the management of obesity in pregnancy in Australia, Ireland, Canada, the United Kingdom and the United States of America all recommend that women try to achieve a 'healthy' weight prior to pregnancy. This is variably defined as a BMI of 18.5-

This article is protected by copyright. All rights reserved. 
$24.9 \mathrm{~kg} / \mathrm{m}^{2}, \mathrm{BMI}<35 \mathrm{~kg} / \mathrm{m}^{2}$ or a loss of $5-7 \%$ of body weight (12). The recommended weight loss targets in clinical guidelines are discordant with actual weight loss achieved using lifestyle modification in clinical trials. For example, for a woman of standard height $(162 \mathrm{~cm})$ with a BMI of $40 \mathrm{~kg} / \mathrm{m}^{2}$, targeting a BMI of $35 \mathrm{~kg} / \mathrm{m}^{2}$ equates to a weight loss of $13 \mathrm{~kg}$. This is $2-4$ times greater than the modest weight loss achieved in clinical trials using non-surgical methods of weight loss. Two studies included in this review achieved much greater weight loss (mean weight loss $10.2 \mathrm{~kg}$ and 26.0 $\mathrm{kg}$ respectively) than the other studies $(79,82)$. There is insufficient detail in methodology of these studies to determine why these studies achieved significantly more weight loss. However, both of these studies recruited women with prolonged infertility and hence these women may have been particularly motivated.

The duration of non-surgical weight loss studies included in this review varied between 3 and 6 months. Interestingly, the longer duration studies did not necessarily achieve more weight loss. This finding is similar to that seen in weight loss studies not related to pre-conception care (102). This suggests that, particularly in older women, pre-conception weight loss should occur over a short well-defined period. Longer duration lifestyle modification programs may not achieve more weight loss and may negatively impact on the chance of pregnancy if fertility is waning due to age.

Some have suggested that pre-pregnancy weight loss may negatively impact the nutritional status of the mother and therefore impair fetal growth and development $(103,104)$. However, it is important to differentiate a clinically recommended weight loss program in a woman with obesity from weight loss due to a decrease in nutritional status. If protein and micronutrient intake are well maintained in the preconception period, there is no evidence that loss of fat mass in women with obesity negatively impacts pregnancy outcomes (105). Conversely, a low protein diet in the pre- 
conception period has been shown to have adverse effects on the fetus in both animal and human studies $(106,107,108)$.

Very Low Energy Diets (VLED) programs cause weight loss by restriction of calories as well as carbohydrate intake which then causes fat to be used as a source of energy (109). The resulting ketosis is associated with transient appetite suppression which may facilitate weight loss (110). Of the studies in this review using a VLED program to achieve weight loss, most study protocols modified the VLED program such that ketosis was questionable. The studies by Sim et al. (83) and Einarsson et al. (75) were an exception to this, but were specific to a population of women with obesity who were using reproductive technology. In these studies, the weight loss program occurred after storage of the oocyte but before implantation of the embryo. Therefore the oocyte is not exposed to the metabolic environment during the VLED program. This is different to women using a VLED program prior to spontaneous conception. The duration of the VLED programs in the study by Einarsson et al. (75) was twice as long as the VLED program in the study by Sim et al.(83) (12 weeks vs. 6 weeks respectively). Although the longer VLED program in the study by Einarsson et al. (75) resulted in more weight loss, live birth rate was higher in the intervention arm of the study by Sim et al. (83) (44\% vs $14 \%$ ). This difference in live birth rate may reflect differences in the study populations.

With the exception of a few small studies, there is limited experience with the use of medications such as phentermine and orlistat in the pre-pregnancy setting. While these studies suggest that modestly more weight loss is achieved using these medications, live birth rate is not substantially improved and other impacts on the fetus are unknown. Two studies in this review used metformin to assist weight loss and fertility $(28,72)$. In the study by Tang et al.(72), weight loss was modest in both the group that used metformin plus lifestyle and the group that used lifestyle alone 
(2.8kg vs $1.5 \mathrm{~kg}, \mathrm{p}=0.06)$. The pregnancy rate was higher in the metformin plus lifestyle group, but this was not statistically significant $(8.7 \%$ vs $2.7 \%, p=0.23)$. As other studies have suggested, metformin may improve fertility via an effect unrelated to weight loss $(111,112)$. No study that involved the use of GLP-1 analogues in the pre-pregnancy setting met the criteria for inclusion in this systematic review, however research is ongoing using this class of agents $(113,114)$.

Consistent with data from weight loss strategies outside the pre-pregnancy setting, studies included in this review show that bariatric surgery results in a greater mean weight loss than nonsurgical methods. Weight loss tends to be greater after malabsorptive procedures (Roux-en $\mathrm{Y}$ gastric bypass (RYGB) and sleeve gastrectomy) than restrictive procedures (laparaoscopic adjustable gastric band (LAGB), vertical banded gastroplasty (VBG)). Regardless of surgery type, weight loss after bariatric surgery is substantial, and in some cases, moves women from an obese to non-obese BMI category. The surgery to conception interval is highly variable, with a significant proportion of women conceiving whilst in a phase of rapid weight loss. The implications of this are still being explored.

Numerous studies in this review suggest there is a benefit of substantial weight loss, achieved through bariatric surgery, on reducing the rate of adverse pregnancy outcomes for the mother. Reduced rates of gestational diabetes and gestational hypertension/pre-eclampsia are reported $(85,86,93,94,99,115)$. This is very important given the known association with premature cardiovascular disease in women who develop these complications in pregnancy (116). However, the impact of substantial weight loss on fetal outcomes is less clear. Several studies in this review suggest a higher rate of small-for-gestational-age infants in women who lost substantial weight after bariatric surgery. This finding was highlighted in the large study by Johansson et al. which reported a

This article is protected by copyright. All rights reserved. 
statistically significant increase in the rate of small-for-gestational-age post bariatric surgery $(15 \% \mathrm{vs}$. $7.6 \%$, OR $2.20, p<0.001)$. This study also suggested a possible increase in neonatal death $(1.7 \%$ vs. $7 \%$, OR $2.29, p=0.06)(85)$

According to Australian (117, 118) and American (119) guidelines, women who are considering bariatric surgery should wait at least 12 to 24 months before attempting to conceive. This is intended to prevent the fetus from being exposed to rapid maternal weight loss and possible undernutrition. In the study by Johannson et al., the median surgery-to-delivery time was 1.8 years (21 months) which means the median surgery-to-conception time was approximately 11 months (85). This finding is replicated in numerous studies (120). Stentebjerg et al. demonstrated that when women were asked to wait at least 18 months to conceive post gastric bypass, two thirds had conceived within this time-frame (121). Interestingly, in the sub-group analysis of the Johannson et al. study, the lowest rate of small-for-gestational-age infants was seen in women who delivered 1224 months post-surgery suggesting a short surgery to conception time may not, in itself, be detrimental to the developing fetus (85). Particularly in the later reproductive years, the benefits of postponing pregnancy to achieve weight loss must be balanced against the risk of declining fertility with advancing age and the nutritional consequences of surgery.

As reflected in international guidelines, the purpose of pre-conception care and nutritional consultation is far broader than weight loss $(122,123)$. Whether weight loss is achieved by surgical or non-surgical methods, protein intake should be maintained during weight loss attempts. Grieger et al. has demonstrated an increase in adverse pregnancy outcomes in women who are protein malnourished in pregnancy (108). Protein and micronutrient deficiencies should be considered in all women who have had bariatric surgery and are considering pregnancy (124). Protein, iron, folate,

This article is protected by copyright. All rights reserved. 
calcium, and vitamins $B_{12}$ and $D$ are the most common nutrient deficiencies after malabsorptive bariatric surgeries $(125,126)$. Post-bariatric surgery, women should remain under the care of a dietician to ensure adequate intake of protein and micronutrients in the months prior to conception. Micronutrient deficiencies are common in women with obesity and hence may exist even in women who achieve only a small amount of weight loss prior to pregnancy. To mitigate against this risk, several guidelines suggest the use of a multivitamin and/or folate in the preconception period (20, $119,127)$.

Pre-pregnancy weight management should occur in conjunction with appropriate weight management during pregnancy. Catalano et al. has shown that even women with obesity who gain inadequate weight during pregnancy $(<5 \mathrm{~kg})$ have a significantly increased risk of small-forgestational-age infants (128). These infants carry the same long-term metabolic risks as large-forgestational-age infants (129). Women should therefore be supported to gain weight during pregnancy according to the 2013 Institute of Medicine guidelines (119). The Institute of Medicine (IOM) is an American non-profit non-governmental body that aims to provide unbiased evidence based authoritative information to improve health outcomes (130). The guidelines for weight gain in pregnancy aim to balance the risks of insufficient weight gain in pregnancy with the risks posed by maternal obesity (131).

The lack of prospective randomised controlled trials investigating the impact of pre-conception weight loss on pregnancy outcomes in women with obesity is clear. Despite this, based on the available data, it appears that weight loss prior to conception improves fertility, and possibly live birth rates, in women with overweight or obesity. This impact is evident regardless of how weight 
loss is achieved. However, the optimal amount, method and timing of weight loss remains unclear. Further, pre-pregnancy care can only be instituted if women present for care prior to conception.

\subsection{Health service related barriers to pre-pregnancy weight loss}

While the cost of providing obstetric care for women with overweight and obesity is known to be higher than normal weight women (45), there is also a cost incurred in the delivery of prepregnancy weight loss interventions (132). In a recent systematic review of the costs of bariatric surgery $(n=45,219)$, the median calculated costs (in US dollars) for Roux-en-Y gastric bypass, sleeve gastrectomy, and adjustable gastric band were $\$ 12,543(\$ 9,970-\$ 15,857), \$ 10,531(\$ 8,248-\$ 13,527)$, and $\$ 9,219(\$ 7,545-\$ 12,106)$ respectively $(133)$. A study exploring the cost of non-surgical weight loss suggested the average cost (in US dollars) per kilogram of weight loss ranged from $\$ 155(95 \% \mathrm{Cl}$ : \$110-\$218) for a lifestyle program (Weight Watchers) to $\$ 546$ (95\% Cl: \$390-\$736) for a pharmaceutical agent (Orlistat). In many cases, these costs are borne by the consumer as public health care services directed at non-surgical obesity management are either limited or absent (134).

\subsection{Evidence Gaps}

8.1 Substantial vs modest weight loss

While most evidence-based guidelines support the concept of weight loss prior to conception in women with obesity, there is no consensus about how much weight loss would be considered 'ideal' for both mother and child. Modest weight loss ( $3-5 \%$ body weight) has metabolic benefits for the mother, improves fertility and causes no harm to the offspring $(74,135,136)$. The impact of substantial weight loss is less clear.

Substantial weight loss achieved through bariatric surgery appears to improve the risks of adverse pregnancy outcomes for the mother but may increase the risks for the offspring (104). It is

This article is protected by copyright. All rights reserved. 
unclear why offspring risks are increased after surgery, but this could reflect the surgery itself, conception during the phase of rapid weight loss, or an altered dietary intake after surgery.

Substantial weight loss could potentially be achieved with a VLED program prior to pregnancy (109). Currently there are only a few small randomised controlled trials which demonstrate the impact of a VLED program on pre-pregnancy weight loss $(73,80,81,83)$ and there are no trials which inform about the impact of VLED-induced substantial weight loss on pregnancy outcomes.

\subsection{Timing of weight loss}

As noted by Catalano, over 50 interventional trials in maternal obesity have failed to demonstrate that limiting gestational weight gain can reduce the incidence of adverse pregnancy outcomes $(137,138,139,140,141)$. If the early metabolic environment plays a critical role in the metabolic health of a pregnancy, and weight loss takes some time to achieve, it is likely that the benefits of weight loss on pregnancy outcomes can only be expected if weight loss occurs prior to conception (142). Conversely, defense of a biological set-point for weight means that most women will regain weight after weight loss. Therefore, the pre-conception weight loss interventions must find a balance between occurring early enough to allow sufficient time for weight loss, but late enough such that weight regain is minimal.

8.3 Which method of weight loss to optimise the health of the offspring?

There are data from animal and epidemiological studies to suggest that severe dietary restriction of the mother in the peri-conception period may negatively impact the long-term health of the offspring (104). Data from offspring of women who have undergone bariatric surgery prior to

This article is protected by copyright. All rights reserved. 
pregnancy would support this theory $(143,144)$. However, it is important to note that these studies focus on either a restriction of all macronutrients, or a restriction of protein. The impact of weight loss achieved using a very low energy diet on offspring health remains to be determined, but may not be similarly detrimental given that protein and micronutrient intake is maintained $(145,146)$.

8.4 Is the evidence base confounded by metabolically healthy women with obesity?

It remains uncertain whether the evidence base for weight management prior to pregnancy is being confounded by 'metabolically healthy' women with obesity, defined as women with obesity who have no other features of the metabolic syndrome (147). Some suggest that these women may dilute the effects of pre-conception weight loss interventions given they are metabolically healthy. Others argue that these people may not have overt metabolic disease but still have abnormal cardiovascular markers including insulin resistance and dysglycaemia (147). Bar et al. recently demonstrated that maternal obesity, even in otherwise metabolically healthy subjects, is associated with an increased rate of placental vascular supply abnormalities (148). This suggests 'metabolically healthy' women should be included in future pre-conception weight loss studies.

\subsection{Summary and Conclusions}

Obesity has reached epidemic proportions globally. The rate of obesity is increasing most rapidly in women of reproductive age. This has important implications for our future delivery of maternity health care. Based on this systematic review, weight loss prior to pregnancy does appear to improve fertility in women with obesity. This effect is noted regardless of how weight loss is achieved. Bariatric surgery results in greater weight loss than non-surgical weight loss techniques. Surgery decreases the risk of pregnancy complications for the mother but may increase risks for the fetus. Non-surgical methods result in only modest weight loss, which has not been shown to impact

This article is protected by copyright. All rights reserved. 
pregnancy outcomes, but is recommended for women with obesity in multiple pre-conception guidelines. It is important that clinicians and patients are aware of the weight loss achieved in nonsurgical weight loss studies, such that expectations of weight loss prior to conception are not unrealistically high. More research is required to determine the optimal amount and method of weight loss for women with obesity who are planning pregnancy.

This article is protected by copyright. All rights reserved. 
1. Chu SY, Kim SY, Bish CL. Prepregnancy obesity prevalence in the United States, 2004-2005. Matern Child Health J 2009;13: 614-620.

2. Mclntyre HD, Gibbons KS, Flenady VJ, Callaway LK. Overweight and obesity in Australian mothers: epidemic or endemic? Med J Aust 2012;196: 184-188.

3. Welfare AloHa. Overweight and obesity in Australia: a birth cohort analysis. 2017.

4. A picture of overweight and obesity in Australia. In: Welfare AloHa (ed). 2017.

5. Keating C, Backholer K, Gearon E, Stevenson C, Swinburn B, Moodie M, et al. Prevalence of class-I, class-II and class-III obesity in Australian adults between 1995 and 2011-12. Obes Res Clin Pract 2015;9: 553-562.

6. Welfare AloHa. A picture of overweight and obesity in Australia. 2017.

7. Walls HL, Magliano DJ, Stevenson CE, Backholer K, Mannan HR, Shaw JE, et al. Projected progression of the prevalence of obesity in Australia. Obesity (Silver Spring) 2012;20: 872 878.

8. Robinson WR, Kershaw KN, Mezuk B, Rafferty J, Lee H, Johnson-Lawrence V, et al. Coming unmoored: disproportionate increases in obesity prevalence among young, disadvantaged white women. Obesity (Silver Spring) 2015;23: 213-219.

9. Bjermo $\mathrm{H}$, Lind $\mathrm{S}$, Rasmussen $\mathrm{F}$. The educational gradient of obesity increases among Swedish pregnant women: a register-based study. BMC Public Health 2015;15: 315.

10. Bahadoer S, Gaillard R, Felix JF, Raat H, Renders CM, Hofman A, et al. Ethnic disparities in maternal obesity and weight gain during pregnancy. The Generation R Study. Eur J Obstet Gynecol Reprod Biol 2015;193: 51-60.

11. Flegal KM, Kruszon-Moran D, Carroll MD, Fryar CD, Ogden CL. Trends in Obesity Among Adults in the United States, 2005 to 2014. JAMA 2016;315: 2284-2291.

12. Kominiarek MA, Chauhan SP. Obesity Before, During, and After Pregnancy: A Review and Comparison of Five National Guidelines. Am J Perinatol 2016;33: 433-441.

This article is protected by copyright. All rights reserved. 
13. Callaway LK, O'Callaghan MJ, McIntyre HD. Barriers to addressing overweight and obesity before conception. Med J Aust 2009;191: 425-428.

14. Grivell RM, O'Brien CM, Dodd JM. Managing Obesity in Pregnancy: A Change in Focus from Harm Minimization to Prevention. Semin Reprod Med 2016.

15. Boulet SL, Johnson K, Parker C, Posner SF, Atrash H. A perspective of preconception health activities in the United States. Matern Child Health J 2006;10: S13-20.

16. Callaway LK, Prins JB, Chang AM, McIntyre HD. The prevalence and impact of overweight and obesity in an Australian obstetric population. Med J Aust 2006;184: 56-59.

17. Aune D, Saugstad OD, Henriksen T, Tonstad S. Maternal body mass index and the risk of fetal death, stillbirth, and infant death: a systematic review and meta-analysis. JAMA 2014;311: 1536-1546.

18. Boney CM, Verma A, Tucker R, Vohr BR. Metabolic syndrome in childhood: association with birth weight, maternal obesity, and gestational diabetes mellitus. Pediatrics 2005;115: e290296.

19. Catalano PM, Shankar K. Obesity and pregnancy: mechanisms of short term and long term adverse consequences for mother and child. BMJ 2017;356: j1.

20. Ma RC, Schmidt MI, Tam WH, Mclntyre HD, Catalano PM. Clinical management of pregnancy in the obese mother: before conception, during pregnancy, and post partum. Lancet Diabetes Endocrinol 2016;4: 1037-1049.

21. Bailie J, Boyle JA, Bailie RS. Population attributable fractions of perinatal outcomes for nulliparous women associated with overweight and obesity, 1990-2014. Med J Aust 2018;208: 505-506.

22. Broughton DE, Moley KH. Obesity and female infertility: potential mediators of obesity's impact. Fertil Steril 2017;107: 840-847.

23. Talmor A, Dunphy B. Female obesity and infertility. Best Pract Res Clin Obstet Gynaecol 2015;29: 498-506.

This article is protected by copyright. All rights reserved. 
24. Bu Z, Dai W, Guo Y, Su Y, Zhai J, Sun Y. Overweight and obesity adversely affect outcomes of assisted reproductive technologies in polycystic ovary syndrome patients. Int I Clin Exp Med 2013;6: 991-995.

25. Ozekinci M, Seven A, Olgan S, Sakinci M, Keskin U, Akar ME, et al. Does obesity have detrimental effects on IVF treatment outcomes? BMC Womens Health 2015;15: 61.

26. Best D, Bhattacharya S. Obesity and fertility. Horm Mol Biol Clin Investig 2015;24: 5-10.

27. Kaye L, Sueldo C, Engmann L, Nulsen J, Benadiva C. Survey assessing obesity policies for assisted reproductive technology in the United States. Fertil Steril 2016;105: 703-706 e702.

28. Kort JD, Winget C, Kim SH, Lathi RB. A retrospective cohort study to evaluate the impact of meaningful weight loss on fertility outcomes in an overweight population with infertility. Fertil Steril 2014;101: 1400-1403.

29. Kiddy DS, Hamilton-Fairley D, Bush A, Short F, Anyaoku V, Reed MJ, et al. Improvement in endocrine and ovarian function during dietary treatment of obese women with polycystic ovary syndrome. Clin Endocrinol (Oxf) 1992;36: 105-111.

30. Ryan DH, Yockey SR. Weight Loss and Improvement in Comorbidity: Differences at 5\%, 10\%, 15\%, and Over. Curr Obes Rep 2017;6: 187-194.

31. Ramachenderan J, Bradford J, McLean M. Maternal obesity and pregnancy complications: a review. Aust N Z J Obstet Gynaecol 2008;48: 228-235.

32. Lashen H, Fear K, Sturdee DW. Obesity is associated with increased risk of first trimester and recurrent miscarriage: matched case-control study. Hum Reprod 2004;19: 1644-1646.

33. Sebire NJ, Jolly M, Harris JP, Wadsworth J, Joffe M, Beard RW, et al. Maternal obesity and pregnancy outcome: a study of 287,213 pregnancies in London. Int J Obes Relat Metab Disord 2001;25: 1175-1182.

34. Chu SY, Callaghan WM, Kim SY, Schmid CH, Lau J, England LJ, et al. Maternal obesity and risk of gestational diabetes mellitus. Diabetes Care 2007;30: 2070-2076.

35. O'Brien TE, Ray JG, Chan WS. Maternal body mass index and the risk of preeclampsia: a systematic overview. Epidemiology 2003;14: 368-374.

This article is protected by copyright. All rights reserved. 
36. Bodnar LM, Catov JM, Klebanoff MA, Ness RB, Roberts JM. Prepregnancy body mass index and the occurrence of severe hypertensive disorders of pregnancy. Epidemiology 2007;18: 234-239.

37. Amir LH, Donath S. A systematic review of maternal obesity and breastfeeding intention, initiation and duration. BMC Pregnancy Childbirth 2007;7: 9.

38. Al Mamun A, Mannan M, O'Callaghan MJ, Williams GM, Najman JM, Callaway LK. Association between gestational weight gain and postpartum diabetes: evidence from a community based large cohort study. PLoS One 2013;8: e75679.

39. Johansson S, Villamor E, Altman M, Bonamy AK, Granath F, Cnattingius S. Maternal overweight and obesity in early pregnancy and risk of infant mortality: a population based cohort study in Sweden. BMJ 2014;349: g6572.

40. Meehan S, Beck CR, Mair-Jenkins J, Leonardi-Bee J, Puleston R. Maternal Obesity and Infant Mortality: A Meta-Analysis. Pediatrics 2014;133: 863-871.

41. Cnattingius S, Villamor E, Johansson S, Edstedt Bonamy AK, Persson M, Wikström AK, et al. Maternal obesity and risk of preterm delivery. JAMA 2013;309: 2362-2370.

42. Alberico S, Montico M, Barresi V, Monasta L, Businelli C, Soini V, et al. The role of gestational diabetes, pre-pregnancy body mass index and gestational weight gain on the risk of newborn macrosomia: results from a prospective multicentre study. BMC Pregnancy Childbirth 2014;14: 23.

43. Rasmussen SA, Chu SY, Kim SY, Schmid CH, Lau J. Maternal obesity and risk of neural tube defects: a metaanalysis. Am J Obstet Gynecol 2008;198: 611-619.

44. Persson M, Cnattingius S, Villamor E, Söderling J, Pasternak B, Stephansson O, et al. Risk of major congenital malformations in relation to maternal overweight and obesity severity: cohort study of 1.2 million singletons. BMJ 2017;357: j2563.

45. Galtier-Dereure F, Boegner C, Bringer J. Obesity and pregnancy: complications and cost. Am J Clin Nutr 2000;71: 1242S-1248S.

This article is protected by copyright. All rights reserved. 
46. Catov JM, Abatemarco D, Althouse A, Davis EM, Hubel C. Patterns of gestational weight gain related to fetal growth among women with overweight and obesity. Obesity (Silver Spring) 2015;23: 1071-1078.

47. Black MH, Sacks DA, Xiang AH, Lawrence JM. The relative contribution of prepregnancy overweight and obesity, gestational weight gain, and IADPSG-defined gestational diabetes mellitus to fetal overgrowth. Diabetes Care 2013;36: 56-62.

48. Mamun AA, Mannan M, Doi SA. Gestational weight gain in relation to offspring obesity over the life course: a systematic review and bias-adjusted meta-analysis. Obes Rev 2014;15: 338347.

49. Sumithran P, Houlihan C, Shub A, Churilov L, Pritchard N, Price S, et al. How common is substantial weight gain after pregnancy? Obes Res Clin Pract 2018;12: 139-145.

50. Zozzaro-Smith PE, Bacak S, Conway C, Park J, Glantz JC, Thornburg LL. Association Between Obesity During Pregnancy and the Adequacy of Prenatal Care. Matern Child Health J 2016;20: 158-163.

51. Morgan KL, Rahman MA, Macey S, Atkinson MD, Hill RA, Khanom A, et al. Obesity in pregnancy: a retrospective prevalence-based study on health service utilisation and costs on the NHS. BMJ Open 2014;4: e003983.

52. Friedman JE. Obesity and Gestational Diabetes Mellitus Pathways for Programming in Mouse, Monkey, and Man-Where Do We Go Next? The 2014 Norbert Freinkel Award Lecture. Diabetes Care 2015;38: 1402-1411.

53. Catalano PM, Farrell K, Thomas A, Huston-Presley L, Mencin P, de Mouzon SH, et al. Perinatal risk factors for childhood obesity and metabolic dysregulation. Am J Clin Nutr 2009;90: 1303-1313.

54. Gaillard R, Steegers EA, Duijts L, Felix JF, Hofman A, Franco OH, et al. Childhood cardiometabolic outcomes of maternal obesity during pregnancy: the Generation R Study. Hypertension 2014;63: 683-691.

55. van Dijk SJ, Molloy PL, Varinli H, Morrison JL, Muhlhausler BS, EpiSCOPE Mo. Epigenetics and human obesity. Int J Obes (Lond) 2015;39: 85-97.

This article is protected by copyright. All rights reserved. 
56. van Dijk SJ, Tellam RL, Morrison JL, Muhlhausler BS, Molloy PL. Recent developments on the role of epigenetics in obesity and metabolic disease. Clin Epigenetics 2015;7: 66.

57. Bays $\mathrm{H}, \mathrm{Scinta} W$. Adiposopathy and epigenetics: an introduction to obesity as a transgenerational disease. Curr Med Res Opin 2015;31: 2059-2069.

58. Whitaker RC. Predicting preschooler obesity at birth: the role of maternal obesity in early pregnancy. Pediatrics 2004;114: e29-36.

59. Zhu Y, Olsen SF, Mendola P, Yeung EH, Vaag A, Bowers K, et al. Growth and obesity through the first $7 \mathrm{y}$ of life in association with levels of maternal glycemia during pregnancy: a prospective cohort study. Am J Clin Nutr 2016;103: 794-800.

60. Andersen LB, Pipper CB, Trolle E, Bro R, Larnkjaer A, Carlsen EM, et al. Maternal obesity and offspring dietary patterns at 9 months of age. Eur J Clin Nutr 2015;69: 668-675.

61. Abdullah A, Wolfe R, Stoelwinder JU, de Courten M, Stevenson C, Walls HL, et al. The number of years lived with obesity and the risk of all-cause and cause-specific mortality. Int J Epidemiol 2011;40: 985-996.

62. Lee KK, Raja EA, Lee AJ, Bhattacharya S, Norman JE, Reynolds RM. Maternal Obesity During Pregnancy Associates With Premature Mortality and Major Cardiovascular Events in Later Life. Hypertension 2015;66: 938-944.

63. Buchanan TA, Xiang AH, Page KA. Gestational diabetes mellitus: risks and management during and after pregnancy. Nat Rev Endocrinol 2012;8: 639-649.

64. Beharier O, Shoham-Vardi I, Pariente G, Sergienko R, Kessous R, Baumfeld Y, et al. Gestational diabetes mellitus is a significant risk factor for long-term maternal renal disease. J Clin Endocrinol Metab 2015;100: 1412-1416.

65. Appiah D, Schreiner PJ, Gunderson EP, Konety SH, Jacobs DR, Nwabuo CC, et al. Association of Gestational Diabetes Mellitus With Left Ventricular Structure and Function: The CARDIA Study. Diabetes Care 2016;39: 400-407.

66. Gaillard R. Maternal obesity during pregnancy and cardiovascular development and disease in the offspring. Eur J Epidemiol 2015;30: 1141-1152.

This article is protected by copyright. All rights reserved. 
67. Gilmore LA, Klempel-Donchenko M, Redman LM. Pregnancy as a window to future health: Excessive gestational weight gain and obesity. Semin Perinatol 2015;39: 296-303.

68. Opray N, Grivell RM, Deussen AR, Dodd JM. Directed preconception health programs and interventions for improving pregnancy outcomes for women who are overweight or obese. Cochrane Database Syst Rev 2015: CD010932.

69. Profile of Health in Australia, Australian Bureau of Statistics. 2013.

70. Zegers-Hochschild F, Adamson GD, de Mouzon J, Ishihara O, Mansour R, Nygren K, et al. International Committee for Monitoring Assisted Reproductive Technology (ICMART) and the World Health Organization (WHO) revised glossary of ART terminology, 2009. Fertil Steril 2009;92: 1520-1524.

71. Posner SF, Johnson K, Parker C, Atrash H, Biermann J. The national summit on preconception care: a summary of concepts and recommendations. Matern Child Health J 2006;10: S197205.

72. Tang T, Glanville J, Hayden CJ, White D, Barth JH, Balen AH. Combined lifestyle modification and metformin in obese patients with polycystic ovary syndrome. A randomized, placebocontrolled, double-blind multicentre study. Hum Reprod 2006;21: 80-89.

73. Legro RS, Dodson WC, Kris-Etherton PM, Kunselman AR, Stetter CM, Williams NI, et al. Randomized Controlled Trial of Preconception Interventions in Infertile Women With Polycystic Ovary Syndrome. J Clin Endocrinol Metab 2015;100: 4048-4058.

74. Mutsaerts MA, van Oers AM, Groen H, Burggraaff JM, Kuchenbecker WK, Perquin DA, et al. Randomized Trial of a Lifestyle Program in Obese Infertile Women. N Engl J Med 2016;374: 1942-1953.

75. Einarsson S, Bergh C, Friberg B, Pinborg A, Klajnbard A, Karlström PO, et al. Weight reduction intervention for obese infertile women prior to IVF: a randomized controlled trial. Hum Reprod 2017;32: 1621-1630.

76. Becker GF, Passos EP, Moulin CC. Short-term effects of a hypocaloric diet with low glycemic index and low glycemic load on body adiposity, metabolic variables, ghrelin, leptin, and pregnancy rate in overweight and obese infertile women: a randomized controlled trial. $A m$ J Clin Nutr 2015;102: 1365-1372.

This article is protected by copyright. All rights reserved. 
77. Clark AM, Ledger W, Galletly C, Tomlinson L, Blaney F, Wang X, et al. Weight loss results in significant improvement in pregnancy and ovulation rates in anovulatory obese women. Hum Reprod 1995;10: 2705-2712.

78. Galletly C, Clark A, Tomlinson L, Blaney F. A group program for obese, infertile women: weight loss and improved psychological health. J Psychosom Obstet Gynaecol 1996;17: 125128.

79. Clark AM, Thornley B, Tomlinson L, Galletley C, Norman RJ. Weight loss in obese infertile women results in improvement in reproductive outcome for all forms of fertility treatment. Hum Reprod 1998;13: 1502-1505.

80. Tsagareli V, Noakes $M$, Norman RJ. Effect of a very-low-calorie diet on in vitro fertilization outcomes. Fertil Steril 2006;86: 227-229.

81. Moran L, Tsagareli V, Norman R, Noakes M. Diet and IVF pilot study: short-term weight loss improves pregnancy rates in overweight/obese women undertaking IVF. Aust N Z J Obstet Gynaecol 2011;51: 455-459.

82. Khaskheli MN, Baloch S, Baloch AS. Infertility and weight reduction: influence and outcome. J Coll Physicians Surg Pak 2013;23: 798-801.

83. Sim KA, Dezarnaulds GM, Denyer GS, Skilton MR, Caterson ID. Weight loss improves reproductive outcomes in obese women undergoing fertility treatment: a randomized controlled trial. Clin Obes 2014;4: 61-68.

84. Galletly C, Clark A, Tomlinson L, Blaney F. Improved pregnancy rates for obese, infertile women following a group treatment program. An open pilot study. Gen Hosp Psychiatry 1996;18: 192-195.

85. Johansson K, Cnattingius S, Näslund I, Roos N, Trolle Lagerros Y, Granath F, et al. Outcomes of pregnancy after bariatric surgery. N Engl J Med 2015;372: 814-824.

86. Dixon JB, Dixon ME, O'Brien PE. Birth outcomes in obese women after laparoscopic adjustable gastric banding. Obstet Gynecol 2005;106: 965-972.

87. Sheiner E, Balaban E, Dreiher J, Levi I, Levy A. Pregnancy outcome in patients following different types of bariatric surgeries. Obes Surg 2009;19: 1286-1292.

This article is protected by copyright. All rights reserved. 
88. Pilone V, Hasani A, Di Micco R, Vitiello A, Monda A, Izzo G, et al. Pregnancy after laparoscopic gastric banding: maternal and neonatal outcomes. Int J Surg 2014;12 Suppl 1: S136-139.

89. Jamal M, Gunay Y, Capper A, Eid A, Heitshusen D, Samuel I. Roux-en-Y gastric bypass ameliorates polycystic ovary syndrome and dramatically improves conception rates: a 9-year analysis. Surg Obes Relat Dis 2012;8: 440-444.

90. Bebber FE, Rizzolli J, Casagrande DS, Rodrigues MT, Padoin AV, Mottin CC, et al. Pregnancy after bariatric surgery: 39 pregnancies follow-up in a multidisciplinary team. Obes Surg 2011;21: 1546-1551.

91. Weiss HG, Nehoda H, Labeck B, Hourmont K, Marth C, Aigner F. Pregnancies after adjustable gastric banding. Obes Surg 2001;11: 303-306.

92. Musella M, Milone M, Bellini M, Sosa Fernandez LM, Leongito M, Milone F. Effect of bariatric surgery on obesity-related infertility. Surg Obes Relat Dis 2012;8: 445-449.

93. Skull AJ, Slater GH, Duncombe JE, Fielding GA. Laparoscopic adjustable banding in pregnancy: safety, patient tolerance and effect on obesity-related pregnancy outcomes. Obes Surg 2004;14: 230-235.

94. Lapolla A, Marangon M, Dalfrà MG, Segato G, De Luca M, Fedele D, et al. Pregnancy outcome in morbidly obese women before and after laparoscopic gastric banding. Obes Surg 2010;20: 1251-1257.

95. Han SM, Kim WW, Moon R, Rosenthal RJ. Pregnancy outcomes after laparoscopic sleeve gastrectomy in morbidly obese Korean patients. Obes Surg 2013;23: 756-759.

96. Ducarme G, Chesnoy V, Lemarié $P$, Koumaré S, Krawczykowski D. Pregnancy outcomes after laparoscopic sleeve gastrectomy among obese patients. Int J Gynaecol Obstet 2015;130: 127-131.

97. Santulli P, Mandelbrot L, Facchiano E, Dussaux C, Ceccaldi PF, Ledoux S, et al. Obstetrical and neonatal outcomes of pregnancies following gastric bypass surgery: a retrospective cohort study in a French referral centre. Obes Surg 2010;20: 1501-1508.

This article is protected by copyright. All rights reserved. 
98. Aricha-Tamir B, Weintraub AY, Levi I, Sheiner E. Downsizing pregnancy complications: a study of paired pregnancy outcomes before and after bariatric surgery. Surg Obes Relat Dis 2012;8: 434-439.

99. Lesko J, Peaceman A. Pregnancy outcomes in women after bariatric surgery compared with obese and morbidly obese controls. Obstet Gynecol 2012;119: 547-554.

100. González I, Rubio MA, Cordido F, Bretón I, Morales MJ, Vilarrasa N, et al. Maternal and perinatal outcomes after bariatric surgery: a Spanish multicenter study. Obes Surg 2015;25: 436-442.

101. Counterweight Project T, McQuigg M, Brown JE, Broom JI, Laws RA, Reckless JP, et al. Engaging patients, clinicians and health funders in weight management: the Counterweight Programme. Fam Pract 2008;25 Suppl 1: i79-86.

102. Team CP. Evaluation of the Counterweight Programme for obesity management in primary care: a starting point for continuous improvement. Br J Gen Pract 2008;58: 548-554.

103. Correia-Branco A, Keating E, Martel F. Maternal Undernutrition and Fetal Developmental Programming of Obesity: The Glucocorticoid Connection. Reprod Sci 2014.

104. Matusiak K, Barrett HL, Callaway LK, Nitert MD. Periconception weight loss: common sense for mothers, but what about for babies? J Obes 2014;2014: 204295.

105. Kurpad AV, Muthayya S, Vaz M. Consequences of inadequate food energy and negative energy balance in humans. Public Health Nutr 2005;8: 1053-1076.

106. Jousse C, Muranishi Y, Parry L, Montaurier C, Even P, Launay JM, et al. Perinatal protein malnutrition affects mitochondrial function in adult and results in a resistance to high fat diet-induced obesity. PLoS One 2014;9: e104896.

107. Lou MF, Shen W, Fu RS, Zhang XY, Wang DH. Maternal dietary protein supplement confers long-term sex-specific beneficial consequences of obesity resistance and glucose tolerance to the offspring in Brandt's voles. Comp Biochem Physiol A Mol Integr Physiol 2015;182: 3844.

108. Grieger JA, Grzeskowiak LE, Clifton VL. Preconception dietary patterns in human pregnancies are associated with preterm delivery. J Nutr 2014;144: 1075-1080.

This article is protected by copyright. All rights reserved. 
109. Delbridge E, Proietto J. State of the science: VLED (Very Low Energy Diet) for obesity. Asia Pac J Clin Nutr 2006;15 Suppl: 49-54.

110. Sumithran P, Prendergast LA, Delbridge E, Purcell K, Shulkes A, Kriketos A, et al. Ketosis and appetite-mediating nutrients and hormones after weight loss. Eur J Clin Nutr 2013;67: 759764.

111. Nawaz FH, Rizvi J. Continuation of metformin reduces early pregnancy loss in obese Pakistani women with polycystic ovarian syndrome. Gynecol Obstet Invest 2010;69: 184-189.

112. Karatas A, Ozlu T, Erdem A. Maternal metformin, obesity, and metabolic syndrome: the contribution of autonomic nervous system function. Am J Obstet Gynecol 2014;210: 282.

113. Glastras SJ, Chen H, McGrath RT, Zaky AA, Gill AJ, Pollock CA, et al. Effect of GLP-1 Receptor Activation on Offspring Kidney Health in a Rat Model of Maternal Obesity. Sci Rep 2016;6: 23525.

114. Nikolic D, Al-Rasadi K, Al Busaidi N, Al-Waili K, Banerjee Y, Al-Hashmi K, et al. Incretins, Pregnancy, and Gestational Diabetes. Curr Pharm Biotechnol 2016;17: 597-602.

115. Amsalem D, Aricha-Tamir B, Levi I, Shai D, Sheiner E. Obstetric outcomes after restrictive bariatric surgery: What happens after 2 consecutive pregnancies? Surg Obes Relat Dis 2014;10: 445-449.

116. Lee KK, Raja EA, Lee AJ, Bhattacharya S, Bhattacharya S, Norman JE, et al. Maternal Obesity During Pregnancy Associates With Premature Mortality and Major Cardiovascular Events in Later Life. Hypertension 2015;66: 938-944.

117. Vitner D, Harris K, Maxwell C, Farine D. Obesity in pregnancy: a comparison of four national guidelines. J Matern Fetal Neonatal Med 2018: 1-11.

118. Kitto SC, Borradale D, Jeffrey CA, Smith JA, Villanueva EV. Bariatric surgery in Australia: who, why and how? ANZ J Surg 2007;77: 727-732.

119. Gynecologists ACoOa. ACOG Committee opinion no. 549: obesity in pregnancy. Obstet Gynecol 2013;121: 213-217.

120. Tsur A, Machtinger R, Segal-Lieberman G, Orvieto R. [Obesity, bariatric surgery and future fertility]. Harefuah 2014;153: 478-481, 497, 496.

This article is protected by copyright. All rights reserved. 
121. Stentebjerg LL, Andersen LLT, Renault K, Støving RK, Jensen DM. Pregnancy and perinatal outcomes according to surgery to conception interval and gestational weight gain in women with previous gastric bypass. J Matern Fetal Neonatal Med 2017;30: 1182-1188.

122. Mullins E, Murphy O, Davies SC. Pre-conception public health to address maternal obesity. BJOG 2016;123: 159-160.

123. Weisman CS, Hillemeier MM, Downs DS, Feinberg ME, Chuang CH, Botti JJ, et al. Improving women's preconceptional health: long-term effects of the Strong Healthy Women behavior change intervention in the central Pennsylvania Women's Health Study. Womens Health Issues 2011;21: 265-271.

124. Shah M, Simha V, Garg A. Review: long-term impact of bariatric surgery on body weight, comorbidities, and nutritional status. J Clin Endocrinol Metab 2006;91: 4223-4231.

125. Aron-Wisnewsky J, Verger EO, Bounaix C, Dao MC, Oppert JM, Bouillot JL, et al. Nutritional and Protein Deficiencies in the Short Term following Both Gastric Bypass and Gastric Banding. PLoS One 2016;11: e0149588.

126. Dogan $\mathrm{K}$, Homan J, Aarts EO, de Boer H, van Laarhoven CJ, Berends FJ. Long-term nutritional status in patients following Roux-en-Y gastric bypass surgery. Clin Nutr 2017.

127. Davies GA, Maxwell C, McLeod L, Gagnon R, Basso M, Bos H, et al. SOGC Clinical Practice Guidelines: Obesity in pregnancy. No. 239, February 2010. Int J Gynaecol Obstet 2010;110: 167-173.

128. Catalano PM, Mele L, Landon MB, Ramin SM, Reddy UM, Casey B, et al. Inadequate weight gain in overweight and obese pregnant women: what is the effect on fetal growth? Am J Obstet Gynecol 2014;211: 137.e131-137.

129. Abell SK, Nankervis A, Khan KS, Teede HJ. Type 1 and Type 2 Diabetes Preconception and in Pregnancy: Health Impacts, Influence of Obesity and Lifestyle, and Principles of Management. Semin Reprod Med 2016;34: 110-120.

130. Blomberg M. Maternal and neonatal outcomes among obese women with weight gain below the new Institute of Medicine recommendations. Obstet Gynecol 2011;117: 1065-1070.

This article is protected by copyright. All rights reserved. 
131. Einerson BD, Huffman JK, Istwan NB, Rhea DJ, Joy SD. New gestational weight gain guidelines: an observational study of pregnancy outcomes in obese women. Obesity (Silver Spring) 2011;19: 2361-2364.

132. Denison FC, Norrie G, Graham B, Lynch J, Harper N, Reynolds RM. Increased maternal BMI is associated with an increased risk of minor complications during pregnancy with consequent cost implications. BJOG 2009;116: 1467-1472.

133. Khorgami Z, Aminian A, Shoar S, Andalib A, Saber AA, Schauer PR, et al. Cost of bariatric surgery and factors associated with increased cost: an analysis of national inpatient sample. Surg Obes Relat Dis 2017;13: 1284-1289.

134. Rowlands I, Graves N, de Jersey S, McIntyre HD, Callaway L. Obesity in pregnancy: outcomes and economics. Semin Fetal Neonatal Med 2010;15: 94-99.

135. Pasanisi F, Contaldo F, de Simone G, Mancini M. Benefits of sustained moderate weight loss in obesity. Nutr Metab Cardiovasc Dis 2001;11: 401-406.

136. Glazer NL, Hendrickson AF, Schellenbaum GD, Mueller BA. Weight change and the risk of gestational diabetes in obese women. Epidemiology 2004;15: 733-737.

137. Catalano P, deMouzon SH. Maternal obesity and metabolic risk to the offspring: why lifestyle interventions may have not achieved the desired outcomes. Int J Obes (Lond) 2015;39: 642649.

138. Dodd JM, Turnbull D, McPhee AJ, Deussen AR, Grivell RM, Yelland LN, et al. Antenatal lifestyle advice for women who are overweight or obese: LIMIT randomised trial. BMJ 2014;348: g1285.

139. Bogaerts AF, Devlieger R, Nuyts E, Witters I, Gyselaers W, Van den Bergh BR. Effects of lifestyle intervention in obese pregnant women on gestational weight gain and mental health: a randomized controlled trial. Int J Obes (Lond) 2013;37: 814-821.

140. Phelan S, Phipps MG, Abrams B, Darroch F, Schaffner A, Wing RR. Randomized trial of a behavioral intervention to prevent excessive gestational weight gain: the Fit for Delivery Study. Am J Clin Nutr 2011;93: 772-779.

This article is protected by copyright. All rights reserved. 
141. Thomson JL, Tussing-Humphreys LM, Goodman MH. Delta Healthy Sprouts: a randomized comparative effectiveness trial to promote maternal weight control and reduce childhood obesity in the Mississippi Delta. Contemp Clin Trials 2014;38: 82-91.

142. Lassance L, Haghiac M, Leahy P, Basu S, Minium J, Zhou J, et al. Identification of early transcriptome signatures in placenta exposed to insulin and obesity. Am J Obstet Gynecol 2015;212: 647.e641-611.

143. Willis K, Sheiner E. Bariatric surgery and pregnancy: the magical solution? J Perinat Med 2013;41: 133-140.

144. Wilson C. Obesity: Does bariatric surgery improve offspring health? Nat Rev Endocrinol 2013;9: 627.

145. Haywood CJ, Prendergast LA, Purcell K, Le Fevre L, Lim WK, Galea M, et al. Very Low Calorie Diets for Weight Loss in Obese Older Adults-A Randomized Trial. J Gerontol A Biol Sci Med Sci 2017.

146. Sumithran P, Proietto J. Safe year-long use of a very-low-calorie diet for the treatment of severe obesity. Med J Aust 2008;188: 366-368.

147. Chiheb S, Cosson E, Banu I, Hamo-Tchatchouang E, Cussac-Pillegand C, Nguyen MT, et al. Are Obese Individuals with no Feature of Metabolic Syndrome but Increased Waist Circumference Really Healthy? A Cross Sectional Study. Exp Clin Endocrinol Diabetes 2016;124: 410-416.

148. Bar J, Kovo M, Schraiber L, Shargorodsky M. Placental maternal and fetal vascular circulation in healthy non-obese and metabolically healthy obese pregnant women. Atherosclerosis 2017;260: 63-66.

This article is protected by copyright. All rights reserved. 
Figure 1: Flow-chart of the extraction of non-surgical pre-conception weight loss articles included in the systematic review.

Databases total $=3249$

Medline $=1232$

PubMed $=957$

Embase $=972$

Cochrane Library $=88$

\section{Bibliography}

search $=3$

Abstracts excluded $=926$

Full-text articles

assessed $=61$

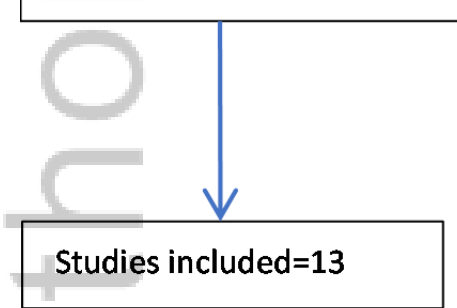

Full-text articles excluded $=48$

1. Meta-analysis/case study $=16$

2. Study intervention not pre-conception $=15$

3. Study population not exclusively overweight/ obese $=8$

4. Not a fertility/pregnancy related $s t u d v=9$

OBR_12804_f1.tif 
Figure 2: Flow-chart of the extraction of surgical pre-conception weight loss articles included in the systematic review.

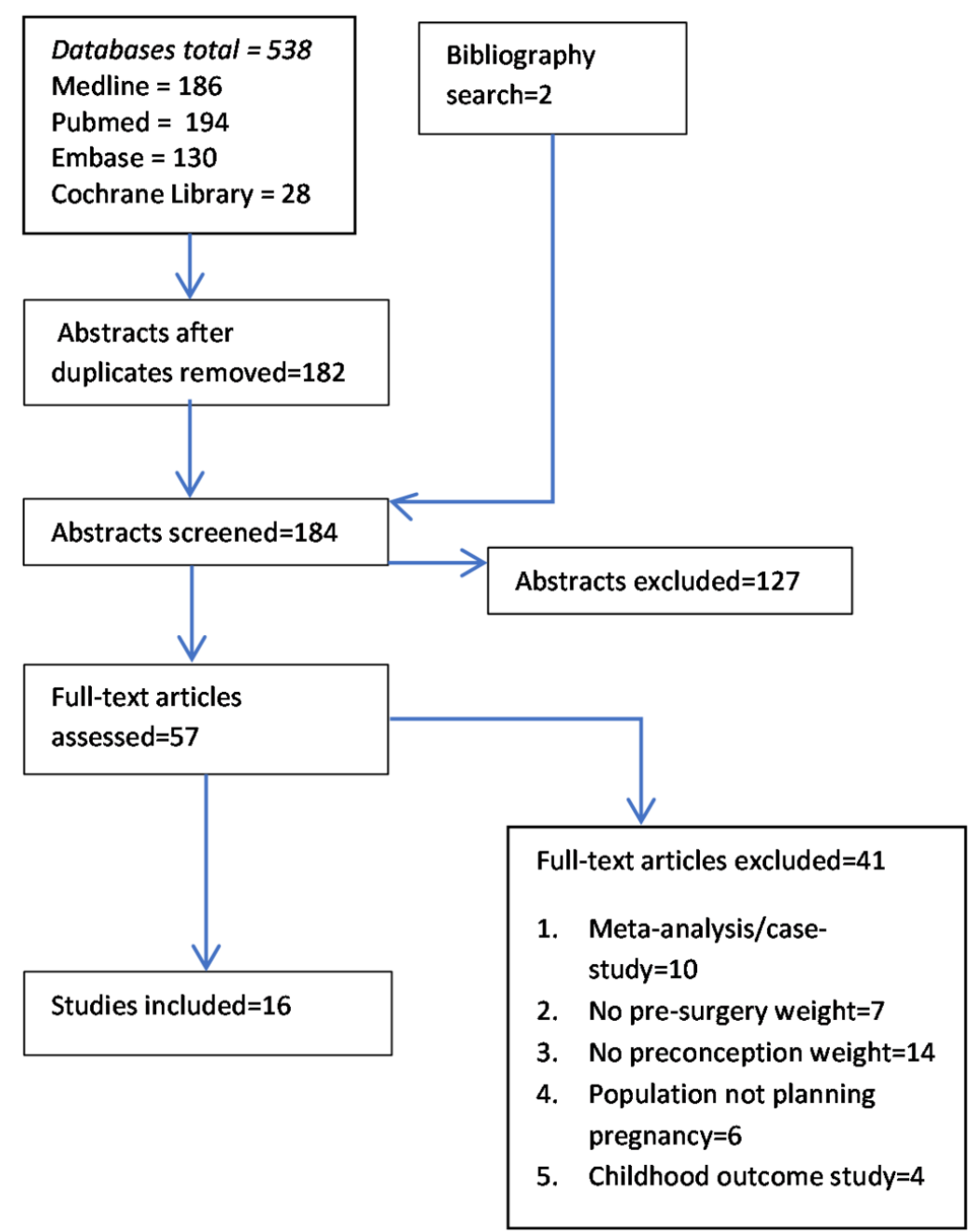

OBR_12804_f2.tif

This article is protected by copyright. All rights reserved. 


\section{University Library}

\section{- M M N E R VA A gateway to Melbourne's research publications}

Minerva Access is the Institutional Repository of The University of Melbourne

Author/s:

Price, SA;Sumithran, P;Nankervis, A;Permezel, M;Proietto, J

Title:

Preconception management of women with obesity: A systematic review

Date:

2019-04-01

Citation:

Price, S. A., Sumithran, P., Nankervis, A., Permezel, M. \& Proietto, J. (2019). Preconception management of women with obesity: A systematic review. OBESITY REVIEWS, 20 (4), pp.510-526. https://doi.org/10.1111/obr. 12804.

Persistent Link:

http://hdl.handle.net/11343/284885 